\title{
Multivariate approaches to the variation in phytobenthic communities and environmental vectors in the Baltic Sea
}

\author{
Hans Kautsky ${ }^{1}$, Eddy van der Maarel ${ }^{2}$ \\ ${ }^{1}$ Department of Zoology \& Askö Laboratory, University of Stockholm, S-106 91 Stockholm, Sweden \\ ${ }^{2}$ Institute of Ecological Botany, University of Uppsala, Box 559, S-751 22 Uppsala, Sweden
}

\begin{abstract}
Q Quantitative data on plant and animal distribution, biomass and environmental data from vegetation-covered bottoms in the northern Baltic proper are analyzed with numerical methods used in modern terrestrial vegetation analysis. The classification and matrix-structuring method TABORD and the ordination method detrended canonical correspondence analysis (DCCA) are described in some detail. The main aim of these multivariate analyses is to correlate environmental factors with detected patterns of species distribution. As the material had already been analyzed by conventional techniques, an evaluation of the multivariate methods was possible. They proved to be of good help in interpreting large data sets from phytobenthic communities. The analyses stress the importance of depth, bottom type and wave exposure, in order of decreasing importance, as the major factors ruling the observed zonation patterns. In contrast with true marine ecosystems, biotic interactions seem to be of minor importance for the establishment of large-scale zonation of phytobenthos in the Baltic Sea.
\end{abstract}

\section{INTRODUCTION}

Although the zonation of the phytobenthos, i.e. the vegetation-covered part of benthic communities, is known in a general way, it is still a matter of dispute whether biotic interactions or environmental factors determine the observed patterns. Lewis (1964) and Stephenson \& Stephenson (1972) described variations in the structure of intertidal communities in the oceans, and Lüning (1985) recently reviewed the zonation of plant species in phytobenthic communities in different parts of the world. These papers discuss observed patterns in relation to abiotic factors such as desiccation, tidal amplitude, wave exposure, depth (i.e. light), temperature, bottom type and salinity. Others have emphasized the importance of biotic interactions, such as intra- and interspecific competition, and e.g. Giller (1984) held that ecological requirements of species and interactions between them are the main determinants for species to coexist. The major type of interaction should be competition for limiting resources, with recruitment and predation being only proximate factors (Giller 1984). Branch (1984) reviewed several marine examples and stated that it is difficult to quantify overlap between species and competitive impact of one species on another in real-world situations. Schiel \& Foster (1986) discussed abiotic and biotic factors as determining spatial and temporal differences in subtidal communities. With the aim of facilitating the interpretation of whether abiotic or biotic factors determine the composition of the community, they subdivide the problem according to different scales: a large, biogeographical scale and a community scale, i.e. they compare between-stand and within-stand variation.

Numerical methods have been used in marine ecology, but, as far as we can judge, not with the same intensity and success as in terrestrial ecology. Early attempts to introduce various numerical techniques to marine biology were made by Neushul (1967), Field \& McFarlane (1968), Field \& Robb (1970) and Boesch (1973). Boesch obtained a 2-way classification of macrobenthos community types and species groups. The approach of Neushul is relevant because it attempts to relate clusters of similar benthic plant species with depth and substrate type along transects. Field et al. (1982) offered a practical strategy for the analysis of benthic samples. Chardy et al. (1976) and Malmgren et al. (1978) evaluated different ordination techniques (for instance PCA) and their application to oceanographic studies. John et al. (1980) and Tittley \& Shaw (1980) 
reviewed classification and ordination methods in phytobenthic communities. Gray et al. (1988) used and evaluated multidimensional scaling and detrended correspondence analysis to characterize soft-bottom benthic macrofauna communities.

Numerical approaches have been more commonly used for soft-bottom benthic communities, e.g. Lie (1978), McLachlan et al. (1984), and Buhl-Jensén (1986). Hughes et al. (1972) used such methods to analyze functional components of the benthos, Poore \& Mobley (1980) in pollution monitoring, Oviatt et al. (1977) in mesocosm studies. Phytobenthic communities were analyzed numerically by Russel (1980), Thom (1980) and Murray \& Littler (1981) in a biogeographic analysis of the intertidal, and by Barton \& Carter (1982) in the evaluation of wave exposure vs species composition and abundance as major factors. Lindström \& Foreman (1978) made a numerical analysis of seaweed communities to determine major environmental factors ruling the species composition, and Weinstein \& Brooks (1983) studied fish communities.

In comparison to these marine approaches the terrestrial ones are far more numerous and diverse (see e.g. Gauch 1982 and Legendre \& Legendre 1983 for recent surveys). Various programs developed and applied with success by terrestrial ecologists have hardly been tried on marine benthos, notably canonical

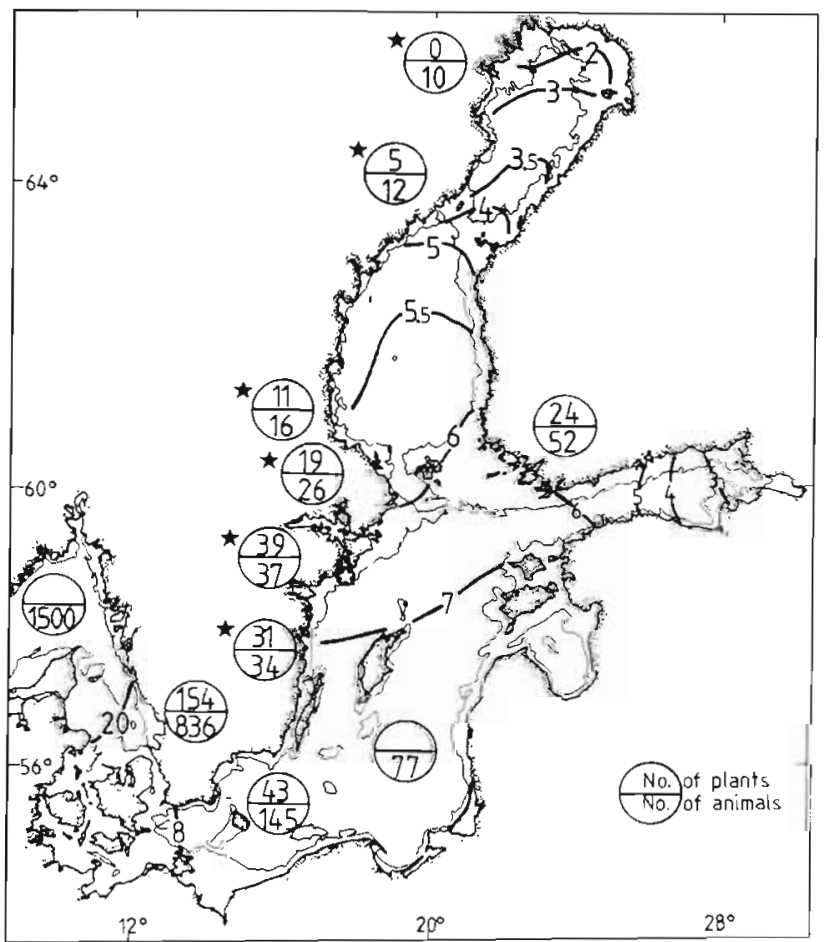

Fig. 1. The Baltic Sea. Isohalines and number of macroscopic plant and invertebrate taxa are indicated. $\mathbf{O}$. Investigated area (Askö). Data summarized from different sources except for those marked are based on quantitative samples (Kautsky) correspondence analysis (Ter Braak 1986, 1987) and cluster analysis combined with tabular ordering (Van der Maarel et al. 1978). We therefore decided to include these methods in a suite of multivariate methods which we applied to phytobenthic material from the northern Baltic proper, assuming that phytobenthic communities and their environment will show similar patterns of variations as terrestrial plant communities do.

For a study of the relation between phytobenthic communities and environmental factors in the Baltic a large amount of material was available, originating from the Askö archipelago in the northern Baltic proper. This has been described briefly by Jansson \& Kautsky (1977) and various intuitive interpretations have been tried regarding the factors controlling the system, but numerical analyses had not yet been applied to the material. The data set includes quantitative distribution data for both algae and benthic animals as well as measurements of various environmental factors.

Our main questions were: (1) To what extent and in which combinations do environmental factors affect the distribution of phyto- and zoobenthos? (2) To what extent can benthic communities, i.e. discrete combinations of benthic organisms, be distinguished and which environmental setting do such communities have? (3) To what degree are phytobenthos and zoobenthos different regarding community composition and environmental distribution?

\section{MATERIAL AND METHODS}

Study area. The Baltic Sea is one of the world's largest brackish water areas. It has a fairly constant salinity gradient, decreasing from 10 to $12 \%$ S inside the sills of the Belt and Öresund areas in the southwest, where the Baltic is connected with the Atlantic Ocean, to less than $3 \% \mathrm{~S}$ in the Bothnian Bay $2000 \mathrm{~km}$ northwards (Siedler \& Hatje 1974, Kullenberg 1983). In the Askö archipelago, salinity is fairly constant around $7 \%$ $\mathrm{S}$ (Fig. 1). Occasional extreme values of down to $5.5 \%$ $\mathrm{S}$ and up to $8 \% \mathrm{~S}$ have been measured in littoral areas.

The low salinity excludes some truly marine species from the area. Consequently the number of marine species in the Baltic is much lower than in the North Sea (Fig. 1). Instead, a few freshwater species are able to survive in the brackish water and may dominate parts of the Baltic ecosystem (for reviews see Magaard \& Reinheimer 1974, Hällfors et al. 1981, Jansson 1984 , Jansson et al. 1984)

Biomass distribution. The brown alga Fucus vesiculosus (L.) dominates the plant biomass in the Askö area (Jansson \& Kautsky 1977). It may form belts from 
about $0.5 \mathrm{~m}$ to $6 \mathrm{~m}$ depth and in its optimal zone between 1 and $3 \mathrm{~m}$ depth it makes up $90 \%$ of the plant biomass, which amounts to a maximum mean biomass of $700 \mathrm{~g}$ dry wt $\mathrm{m}^{-2}$. The species is associated with many other algae and animals. Below $6 \mathrm{~m}$ depth, with decreasing light intensity, the red algae Furcellaria lumbricalis (Lyngb.), Phyllophora pseudoceranoides [(Gmel.) Newroth \& Taylor], P. truncata [(Gmel.) Newroth \& Taylor], Ceramium tenuicorne [(Kütz.) Waern], C. rubrum [(Huds.) C.Ag.] and Rhodomela confervoides [(Huds.) Silva] take over and form a red algal belt. At exposed sites Fucus is absent and is replaced mainly by Ceramium tenuicorne and Furcellaria lumbricalis. The filter-feeding blue mussel Mytilus edulis (L.) is abundant in the algal belts and may form almost monospecific dense mats on deeper hard substrata, when light intensity is too low for the algae.

Mytilus edulis usually makes up over $95 \%$ of the total animal biomass. The mass occurrence of Mytilus is explained by the lack of major predators such as the starfish Asterias rubens (L.) and the crab Carcinus maenas (L.) which are excluded from the Baltic by low salinity (Kautsky 1981). The main phytobentic components found in the northern Baltic proper are illustrated in Fig. 2.
Sampling method. The sampling technique used in the field has been described by Jansson \& Kautsky (1977). Sampling was done in June-July 1974 and 1975. On a detailed and magnified navigation map (scale ca $1: 500$ ) of the area under study at the Asko Laboratory, 32 transects were randomly placed across the $3 \mathrm{~m}$ depth contour. The latter depth contour was chosen in order to obtain a fair representation of softbottom bays in relation to the predominant hard bottom type (rocks) in the area and to obtain samples from some shallow areas that did not reach above the water surface (cf. Jansson \& Kautsky 1977). Transects were of different lengths extending from the shore until hard bottoms or vegetation cover ended. At the transect a meter-marked cord was placed perpendicularly to the shore, along which SCUBA-divers determined the degree of areal cover of different species identified under water, using the following percent scale: 100,75 , $50,25,10$ and $5 \%$, and + indicating presence. Species zonation was characterized and zone width of major belts was determined using the cover of dominant species along the cord. Divers also estimated factors such as distance from shore, width of zone, depth (determined by a calibrated depth gauge), slope, bottom type and amount of silt (sediment) on the bottom.
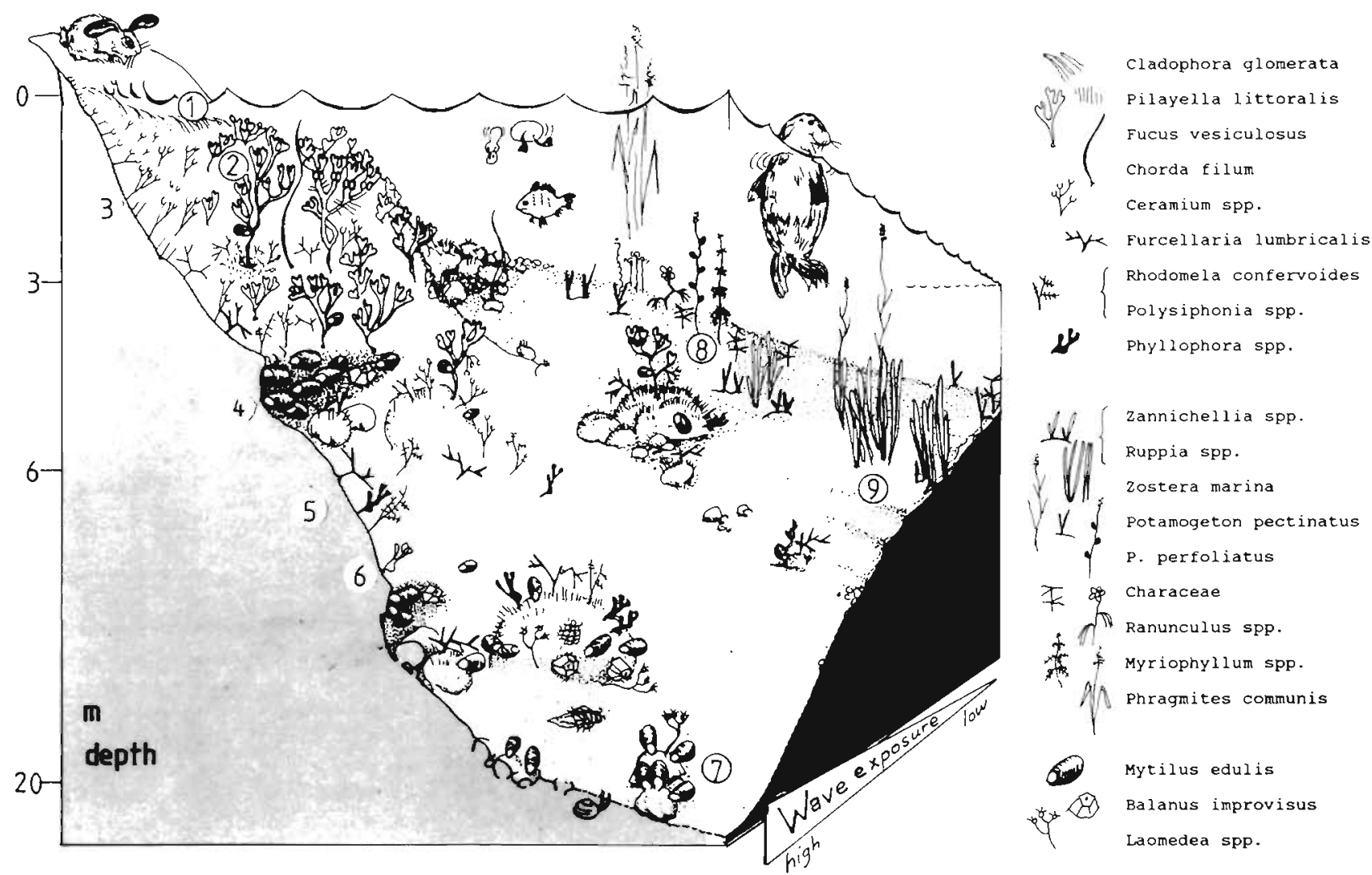

Fig. 2. Naturalistic view of main groupings of different belt forms found in the northern Baltic proper. 1: Cladophora, 2: Fucus, 3: Ceramium, 4: Mytilus-wall, 5: Furcellaria, 6: Phyllophora, 7: deep Mytilus-Laomedea, 8: Potamogeton-Ruppia, 9: ZosteraPotamogeton belt 
Within each identified belt, parallel quantitative samples were taken at random, using quadrants with side lengths of $0.15,0.2$ and $0.5 \mathrm{~m}$, depending on the density and type of the communities (Dybern et al. 1976). In total, data from 282 quantitative samples from 32 transects are used in this investigation. Samples were sorted to species (or nearest higher taxon) of all benthic plants and animals. Number of species and biomass after drying at $60^{\circ} \mathrm{C}$ to constant weight were determined. Biomass is given as $\mathrm{g}$ dry $w t \mathrm{~m}^{-2}$, including shells, when present.

Data analysis. The most accurate and objective data we had at our disposal were the biomass values for each of the 282 samples, which vary from $0.01 \mathrm{~g}$ to $3700 \mathrm{~g}$ dry wt $\mathrm{m}^{-2}$, i.e. by more than 6 orders of magnitude. (Species with extremely low biomass were given a minimum score of 0.001). From previous experience (reviewed by Van der Maarel 1979a) we know that if the highest scores in a matrix are much higher than the lowest ones, results of any multivariate treatment will be entirely determined by the variation in scores for the one or few dominant species, in our case Mytilus edulis and Fucus vesiculosus.

A roughly geometrical scale with the next upper class limit 3 times the former one (as also recommended by Jensén \& Van der Maarel 1980 for aquatic macrophytes) proved to be a satisfactory transformation with classes from 9, corresponding to dry weight values of $510 \mathrm{~g}$ up to the maximum of $3700 \mathrm{~g} \mathrm{~m}^{-2}$ found in the analysis, to 1 , for values 0.01 to $0.1 \mathrm{~g}$. Dry weight values of 5.2 to $17.1 \mathrm{~g}$ $\mathrm{m}^{-2}$, i.e. less than $0.5 \%$, then fall in the median class 5 .

The multivariate methods used in this study are all part of the program packages available at the Institute of Ecological Botany, Uppsala University for use on VAX systems (see Van der Maarel 1979b, Gauch 1982 and Digby \& Kempton 1987 for some basic principles and reviews of methods).

Classification programs. We initially used the program TWINSPAN (Hill 1979a). This divisive program creates clusters of samples by successively subdividing the ensemble. The program is very fast and usually gives a clear picture of the main groupings. One shortcoming is that species which are rare in the material and moreover occur in species-poor samples will determine the arrangement of samples. Hence, the TWINSPAN cluster structure may not always represent the main groupings in a effective way. Another shortcoming (which it shares with other divisive methods) is the inability to correct the position of samples which have been misclassified in an earlier subdivision.

The program TABORD (Van der Maarel et al. 1978) starts with a classification array of clusters which is either generated by the program, or determined by the user, usually based on the results of some earlier classification program, for instance TWINSPAN It first optimizes the position of samples by relocating them to another cluster if the resemblance (based on the quantitative scores of the species involved) with the centroid of that cluster is higher than that with its own cluster. After relocation the 2 most similar clusters are fused The samples are relocated in the new cluster array, etc until either the number of clusters reaches the number determined by the user, or the similarity between the next 2 clusters to be fused would fall below a fusion limit determined by the user. Clearly, the optimum final cluster array is considered in terms of both withinand between-cluster similarity. The next step is the presentation of the resulting clusters in a structured table with the clusters and species arranged so as to obtain a diagonal structure in the table

TABORD's strong points are (1) the establishment of relatively homogeneous groups with relatively high number of species occurring at high frequencies; (2) the creation of a net structure (reticulate clustering) rather than a hierarchical structure (as in TWINSPAN). A shortcoming is that the final cluster array is somewhat dependent on the number of initial clusters chosen. This can be remedied by starting with small groups, ultimately the individual samples as 1 -sample clusters. More generally there is a subjective element in the program. However, as emphasized by Van der Maarel et al. (1987) the apparently more objective program TWINSPAN has many options and hence subjective elements as well.

Ordination programs. First, the programs ORDINA, a principial components analysis (see Van der Maarel 1979a), and RA (reciprocal averaging, Hill 1979a, as mentioned above under TWINSPAN) were used to detect major lines of compositional variation. Since the results appeared to be of no additional help in further explaining the cluster structure with the clustering programs these programs will not be further discussed.

Then the program CANOCO (Ter Braak 1985, 1986, 1987) was applied. This program performs a so-called canonical correspondence analysis, which is based on correspondence analysis as developed by Hill (1979a, b) and Hill \& Gauch (1980). Normal correspondence analysis, CA, is a form of principal component analysis in which samples and species are ordinated simultaneously by assigning scores to each sample and each species so as to maximize the correlation between both (see also Gray et al. 1988). We also used the detrended version, DCA.

The canonical variant of DCA devised by Ter Braak (1985, 1986, 1987) and called DCCA implies that variables other than the species, usually environmental variables, are included in the analysis and that a multiple regression is performed on the external variables on the DCA ordination scores and the original sample scores from DCA are replaced by the scores predicted by the regression. 
As a result correlations between vectors of sample scores and external vectors are maximized. In our case we had data on 7 environmental variables: distance from shore, depth, bottom type, degree of wave exposure, amount of silt, orientation towards compass direction and steepness of slope, as well as on 3 other external variables: profile number, region and time of sampling, and 2 implied biotic variables: belt type and total degree of cover.

It appeared most effective to run DCCA on the ensemble of 282 samples, 97 taxa and 12 external variables

\section{RESULTS}

\section{Floristic and faunistic structure}

Among the 40 plant and 57 animal taxa in the data set, 4 plants occur in more than $50 \%$ of the samples, Ceramium tenuicorne (>90\%), Polysiphonia spp. (>75\%), Furcellaria lumbricalis and Phyllophora spp. (Fig. 3a). Of the 40 plant taxa found in the samples 17 $(43 \%)$ occur in more than $10 \%$ of the samples.

The most abundant animals are Mytilus edulis and Gammarus spp. occurring in more than $95 \%$ of the samples, Hydrobia spp. in more than $90 \%$, and Theodoxus fluviatilis and Jaera albifrons occurring in more than $50 \%$ of the samples (Fig. 3b). Out of 57 animal taxa, $22(39 \%)$ occur in more than $10 \%$ of the samples.

\section{Community structure}

A TWINSPAN run with standard options resulted in a cluster structure with 29 clusters and 10 outlier 1 sample clusters, which was then treated with TABORD (with the Similarity Ratio as resemblance measure). The resulting cluster structure revealed further outlier samples and heterogeneous small clusters which were subdivided. The resulting structure with 35 clusters appeared to be optimal in terms of identifying and differentiating taxa. The procedure followed here reflects the fact that groupings of plants and/or animals have different optimum homogeneity levels, which is largely determined by local differences in total number of taxa per grouping and the relative dominance of one or few taxa. Programs such as TWINSPAN are inflexible in this respect and present a cluster structure at one level of homogeneity throughout.

The resulting 35 -cluster structure can be characterized as follows: Eleven clusters are 1-sample clusters. Most of them are poor in characteristic species and poor in biomass production. Six of them come from the shallow Cladophora belt, and another 2 from samples from the shallow, highly wave-exposed Ceramium belt. The heterogeneity of the area, with highly unpredictable environmental parameters such as weatherinduced longer or shorter periods of desiccation and wave force, cause multiple solutions of species composition due to chance effects. The remaining 26 clusters are presented in Fig. 4 and Table 1.

No less than 7 of those isolated groupings lack the main species Mytilus edulis. Most of the 1-sample clusters are moreover compositionally isolated both towards the bigger groupings and towards each other The highest similarity value with any of them is 0.65 , whereas most values are below 0.40 .

Out of the 97 taxa, 34 show a high frequency in one or more clusters. Nearly all of them are distinguished down to the family or order level. They are used for the final interpretation together with 2 taxa, Lymnaea spp., which occurs with a relatively high score in the 1sample cluster 31, and Potamogeton pectinatus, which occurs only in the 2 related clusters 33 and 18 , albeit with frequency $<60 \%$. Of these 36 differentiating taxa, 21 are plants and 15 are animals, giving a plantanimal ratio of 1.4 to 1 . Since the ratio total plants/total animals is 0.7 to 1 we may say that there are twice as many differentiating plant taxa as expected on the basis of an equal representation.

Of the differentiating taxa 14 occur optimally or exclusively in only 1 or 2 clusters. They may be called character taxa (see Table 2 ) and the plant-animal ratio here is 2.5 to 1 . Amongst these 7 are algae and 3 vascular plants. Apparently the plant taxa involved in this study have more clear-cut patterns of discontinuous occurrence in relation to environmental variation than the animal taxa: compare the ratio 2.5 to 1 with the ratios 1.4 or 0.7 to 1 mentioned above

Regarding the exclusiveness of the clusters: only a few of the clusters have more than one character taxon (Table 2) and of the 10 taxa involved in this observation only 3 are animals. These clusters all have a large number of constant taxa (i.e. having a frequency of over $60 \%$ ). On the other hand, there are clusters with only a few constant taxa. The variation in clear-cutness and identifiability of the clusters obtained is related to the relative position of the clusters towards the local extremes in certain environmental factors, as will be explained in the next section.

To facilitate the environmental interpretation of the clusters, the ordered cluster table obtained with TABORD was re-ordered to follow as closely as possible the main axis of the canonical analysis which is an expression of the interrelated effect of distance to shore and water depth (to be discussed later). The sequence in a TABORD output is obtained by first taking the 


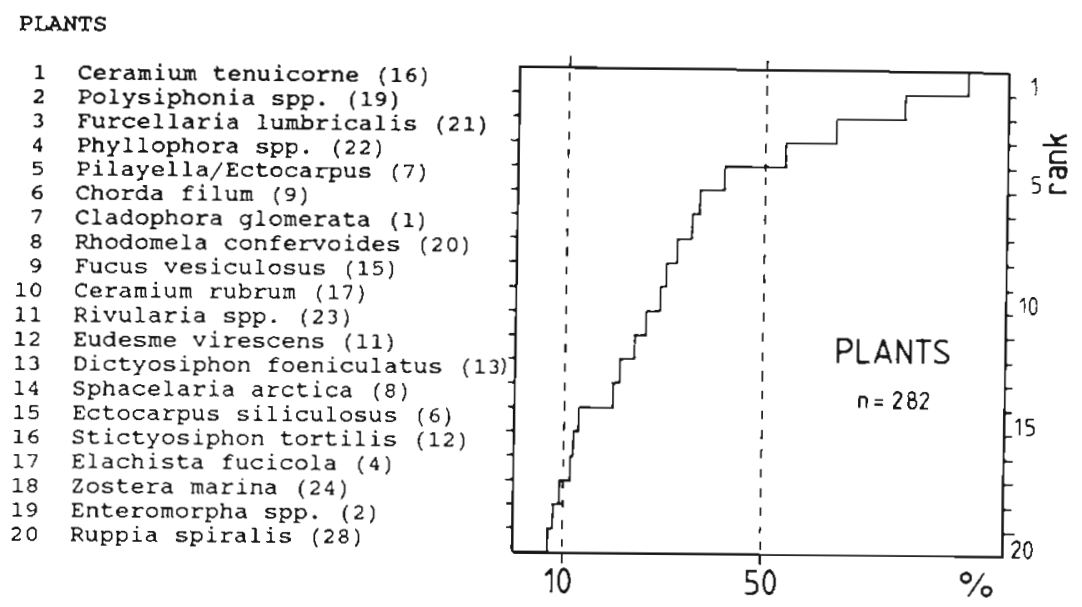

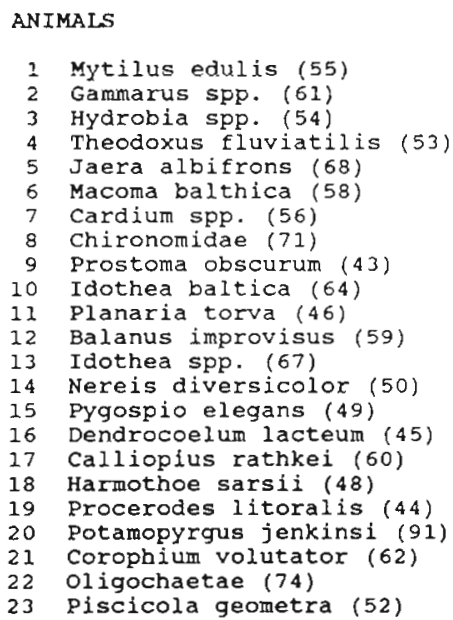

cluster with a relatively large number of samples and relatively few constant species, which is usually a cluster in the compositional center of the data set. From this cluster a diagonal structure is built up by next taking the clusters which share the highest number of constant species. In this way the table structure is visualized optimally. On the other hand, the sequence of the clusters obtained will not necessarily reflect a major environmental gradient.

To further facilitate the interpretation of the cluster structure a simple hierarchical agglomerative clustering was performed on the 26 clusters and 36 taxa selected, with the Similarity Ratio as similarity coefficient and the Weighted-Pair Group Average as fusion criterion. The entry for each taxon in each cluster was calculated from the product of its frequency and its average transformed score. The resulting values were rounded off to the nearest digit, so that again a 1 to 9 scale was obtained. The resulting dendrogram is presented in Fig. 4 in such a way that the individual clusters are ordered as closely as possible in relation to the main environmental axis.
Table 1 presents the resulting sequence of the 26 clusters with the 36 taxa ordered so as to maximally represent the diagonal structure as produced by the original TABORD-table.

Five main groups of clusters can be derived from Fig. 4. The first cluster group $(A)$ is heterogeneous, with low within-group similarity and characterized by samples from shallow sites. The groups in Fig. 4 can be interpreted in terms of their composition as presented in Table 1:

(A) Cladophora-Rivularia group: poor in constant taxa and compositionally little differentiated, mainly through relatively high values for the named taxa, low ones for Mytilus edulis, and the almost exclusive occurrence of Enteromorpha spp.

(B) Ceramium tenuicorne group: poorly differentiated mainly by high scores for $C$. tenuicorne and the lack of Fucus vesiculosus.

(C) Fucus vesiculosus-Ceramium tenuicorne group with Fucusand Cardium as abundant species. This group contain the relatively isolated clusters 18 and 13 which include Zostera marina and Potamogeton pectinatus. 
Fig. 4. Classification dendrogram of the 26 remaining clusters from the TABORD analysis. Status of environmental factors indicated with dark fields. Cluster number and no. of samples (n) for each branch are given. - Cluster contains samples only from the first year of investigation ${ }^{\bullet} \bullet$ only samples from the second year

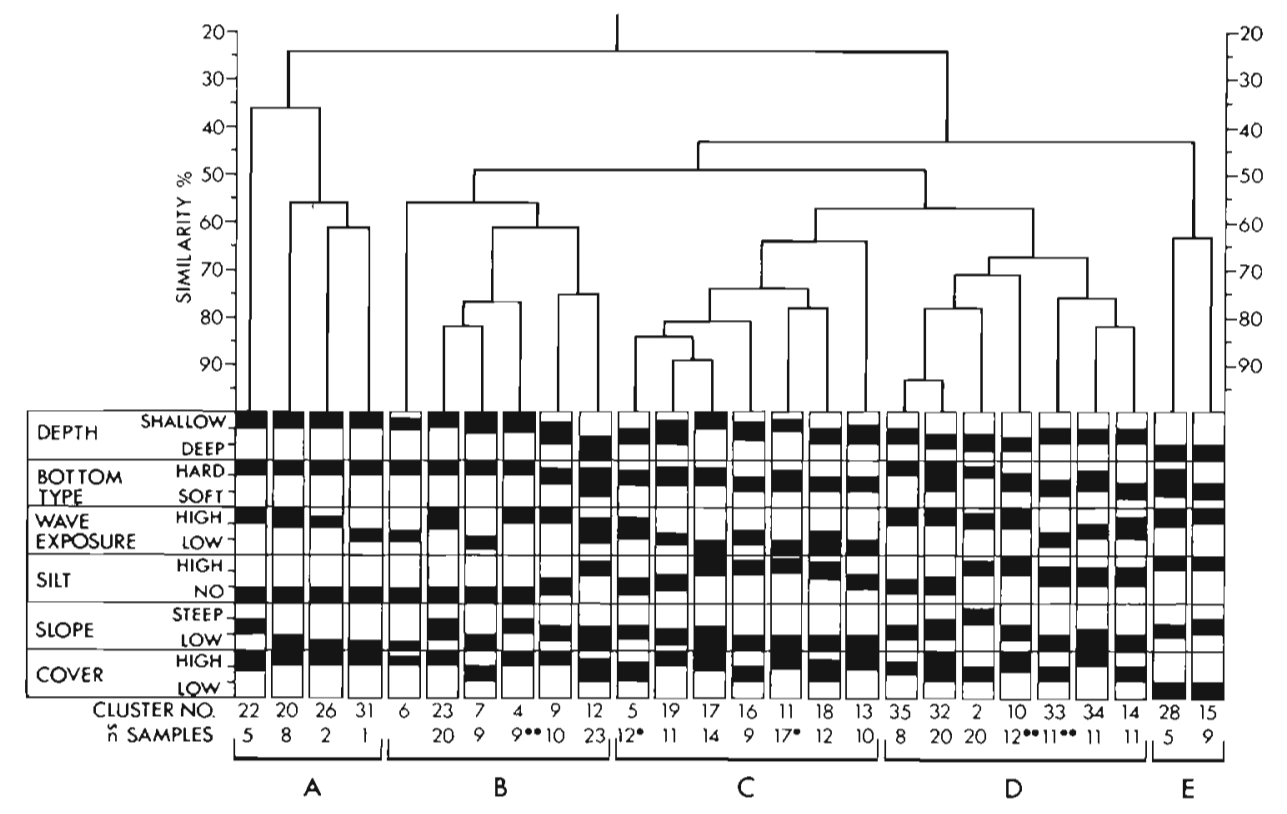

(D) A red algae group Ceramium-Furcellaria lumbricalis with Phyllophora and Rhodomela as further differentiators.

(E) Algae-poor group, very poor in taxa, especially in algae and characterized mainly by the monospecific dominance of the mollusc Mytilus edulis in the small cluster 28 and the combined dominance of the molluscs M. edulis and Macoma balthica in the small cluster 15 .

\section{Ecological structure}

Fig. 4 shows the coherence of the clusters and cluster groups with the main environmental factors involved in the study. With the exception of clusters 9 and 12 the cluster coherence in groups is confirmed by ecological coherence. The clearest differentiation is brought about by depth, bottom type and amount of silt (being highly correlated with depth and wave exposure). From left to right in the table we observe that groups A and $B$ occur in shallow water on hard bottom without silt; groups C and D vary in the environmental characters depth and silt with a clear trend to deeper water and softer bottom type towards the right. Group E occurs in deep water with a high silt content on mixed bottoms.

Regarding exposure to waves the pattern is different. The clusters at the opposite ends of the figure, 22 and 20 in shallow water, 28 and 15 in deep water, are both highly exposed to waves. As shown in Table 2, this is compositionally reflected in the decreased biomass values of Mytilus edulis and Hydrobia spp. in clusters 22 and 20 as compared to the related clusters 26 and 31 . and in the decreased value of Furcellaria lumbricalis and Phyllophora sp. in cluster group E as compared with group D. In the middle of the figure the groups vary: generally high exposure in groups B and D, lower exposure in C. Clearly, there are at least 2 factor complexes acting independently on taxon composition.

The importance of wave exposure as factor determining community composition is demonstrated within each group, through a gradient with decreasing wave exposure towards the right of the group in the dendogram. Also in group $E$ of the deepest bottoms the occurrence of hard bottom communities can only be explained by the high turbulence, preventing the bottoms from turning into a soft-bottom community.

Regarding the coherence between clusters and belts, there is a clear pattern, largely because of the natural correlation between type of belt and water depth (see below).

A correlation matrix for the different axes and environmental factors used in the analysis is presented in Fig. 5. The first 2 species axes in the DCCA run are highly correlated to depth (68 and $65 \%$ ). The first species axis is also correlated to belt code $(73 \%)$, bottom type $(54 \%)$ and silt content $(48 \%)$. The second species axis is correlated to wave exposure $(49 \%)$. The first and second environmental axis have the same pattern of correlations to the environmental vectors as the species axis, although the correlation values are somewhat higher. The environmental vectors depth, bottom type and wave exposure are highly independent from each other, which is reflected in being almost perpendicular to each other (see Fig. 7). Other vectors are more correlated, partly due to ecologically relevant 


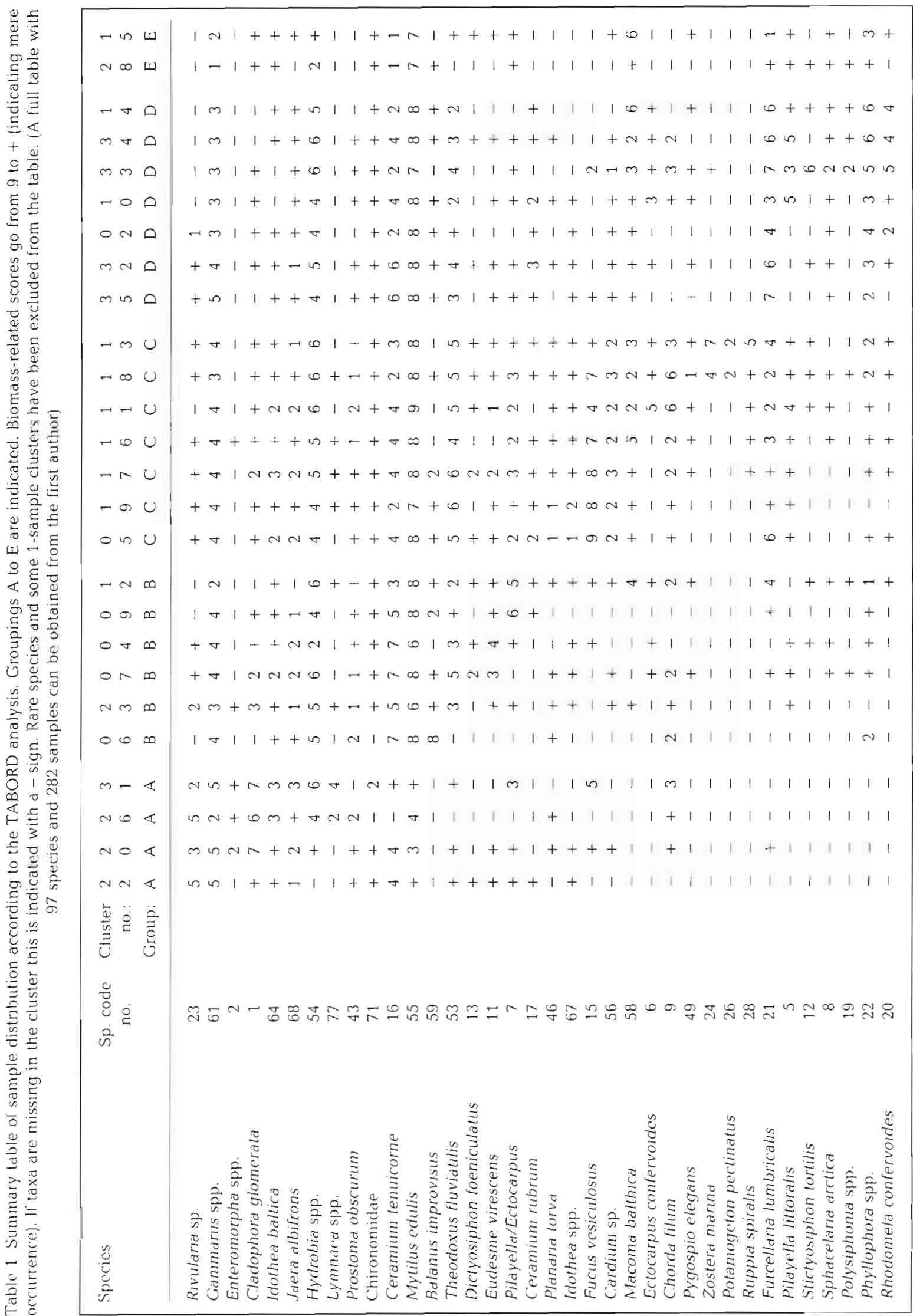


Table 2. List of taxa with optimal occurrence in 1 or 2 clusters only. (Sequence of clusters follows that in Table 1)

\begin{tabular}{|c|c|c|c|c|c|c|c|c|c|c|c|c|c|c|}
\hline Taxon & \multicolumn{14}{|c|}{ Cluster number } \\
\hline Enteromorpha sp. & 20 & & & & & & & & & & & & & \\
\hline Lymnaea spp. & & 26 & 31 & & & & & & & & & & & \\
\hline Eudesme virescens & & & & 7 & 4 & & & & & & & & & \\
\hline Dictyosiphon foeniculatus & & & & 7 & & & & & 17 & & & & & \\
\hline Balanus improvisus & & & & & & 9 & & & 17 & & & & & \\
\hline Planaria torva & & & & & & & 5 & 19 & & & & & & \\
\hline Ectocarpus confervoides & & & & & & & & & & 11 & & & 10 & \\
\hline Zostera marina & & & & & & & & & & & 18 & 13 & & \\
\hline Potamogeton pectinatus & & & & & & & & & & & & 13 & & \\
\hline Ruppia spiralis & & & & & & & & & & & & 13 & & \\
\hline Stictyosiphon tortilis & & & & & & & & & & & & & & 33 \\
\hline Sphacelaria arctica & & & & & & & & & & & & & & 33 \\
\hline Polysiphonia spp. & & & & & & & & & & & & & & 33 \\
\hline
\end{tabular}

factors, for instance belt code to bottom type and depth, or ecologically irrelevant correlations as for instance between profile number and day number (profiles were sampled almost chronologically), distance from shore to depth or wave exposure to region.

The correlation between the main axis of compositional variation and the environmental factors involved as elaborated with DCCA is shown in Figs. 6 to 8. Note that the axis values have no ecological meaning but are more or less correlated to various environmental factors, which in turn are illustrated as vectors in Fig. 7.

Fig. 6 shows the configuration of samples in the diagram of DCCA axes 1 and 2. In addition to the individual samples the centroids of the TABORD clusters are indicated. There is a clear compositional gradient from the Cladophora-Rivularia group (A) at the left side

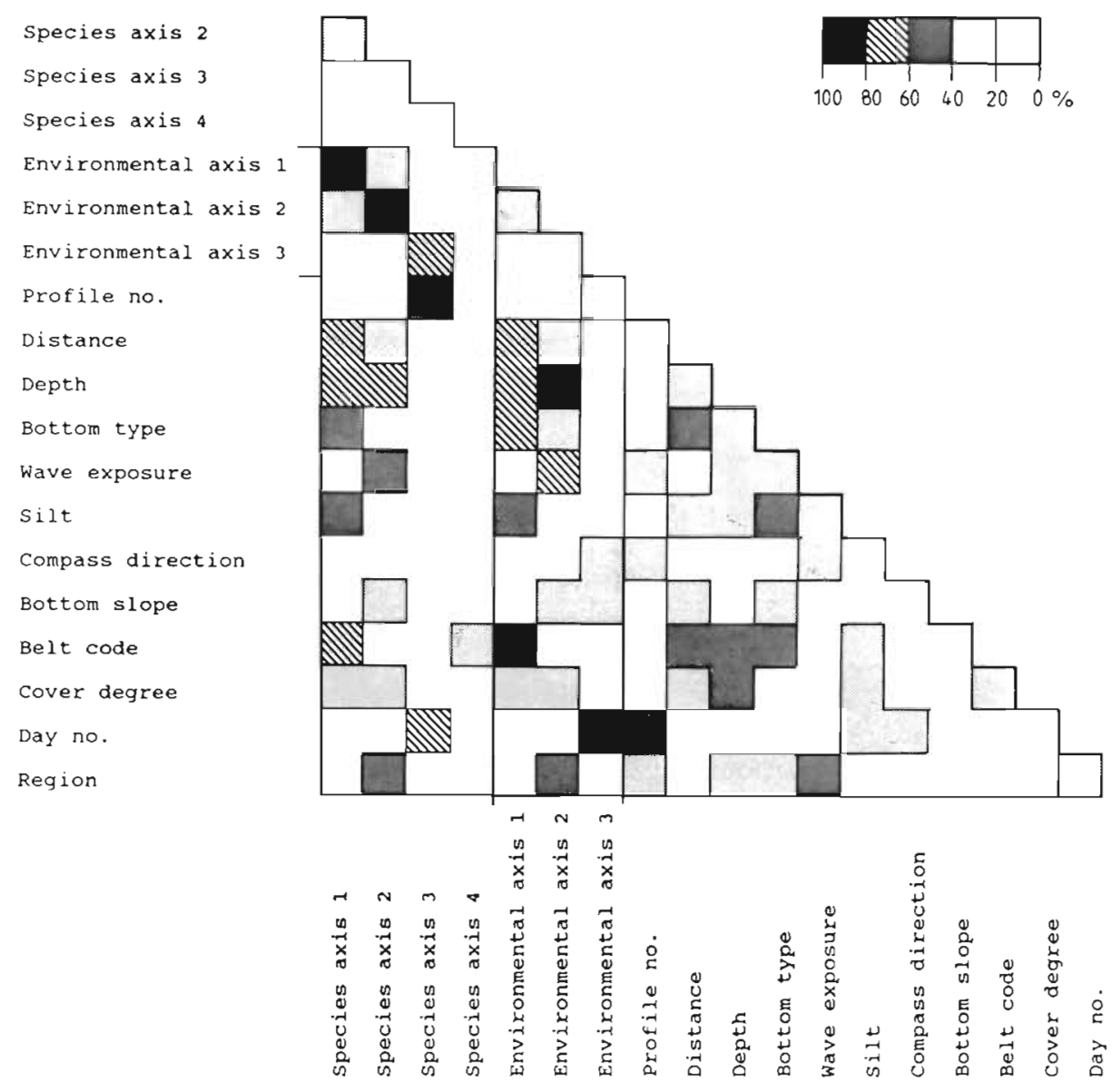

Fig. 5. Correlation matrix for axes and environmental factors from the DCCA run 


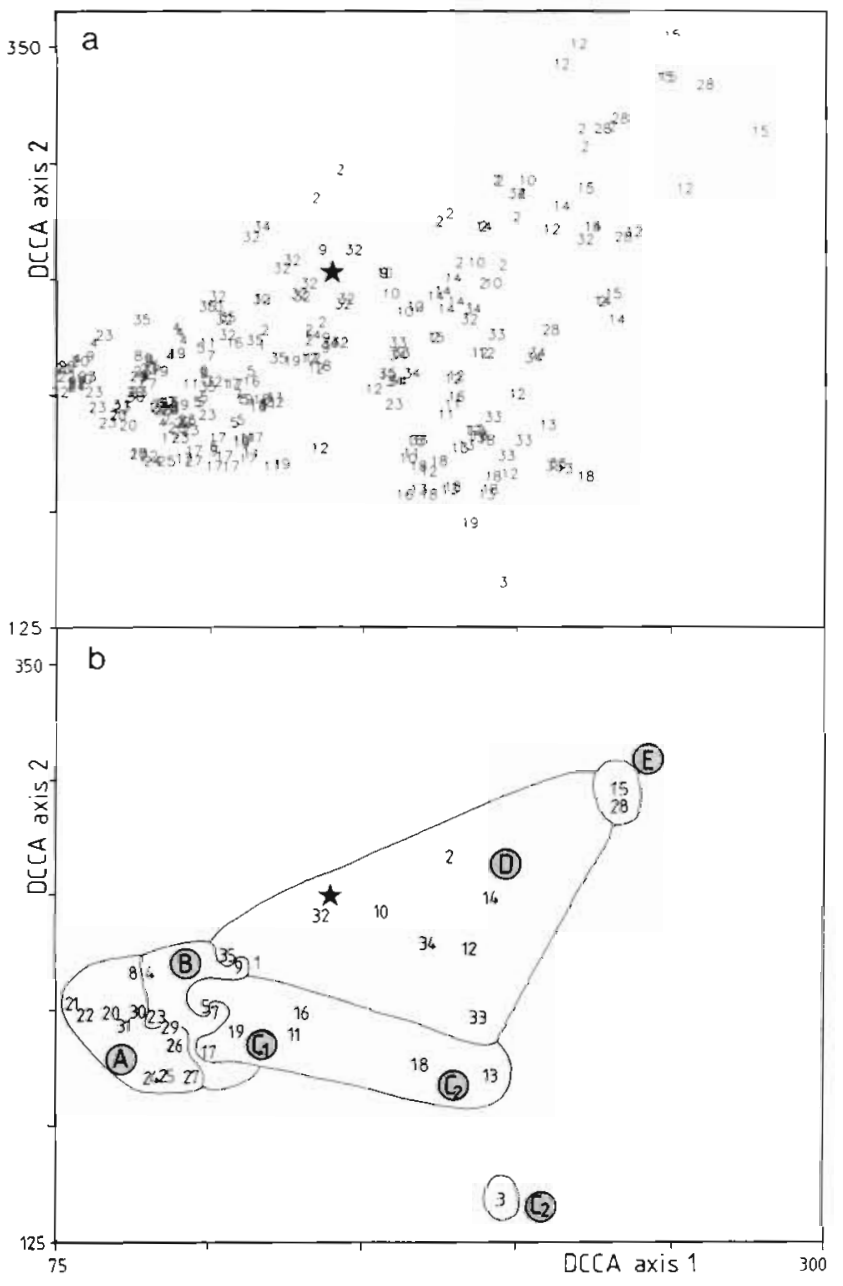

Fig. 6. (a) Sample distribution along the first and second axis of the DCCA analysis. Cluster number from the TABORD analysis is plotted. ( $\star$ ) Centroid of all samples. (b) Centroids from each cluster group given in (a) and position of TABORD cluster groups given in Table 1 and Fig. 4 are encircled and indicated with letters $A$ to $E$

of axis 1 via the Ceramium tenuicorne group B, and part of group D (clusters 32, 2, 10 and 14) to the algaepoor group E (Fig. 6b). A second compositional gradjent runs from clusters 32,2 and 10 from group D to clusters 18,33 and 13 from group $C$, the Fucus vesiculosus-Ceramium spp. group with clusters 18 and 13 representing the Zostera marina and Potamogeton pectinatus belts. These patterns follow the observable field distribution of belts in a chronological way.

Fig. 7 shows the distribution of the taxa in the same space as well as the length and direction of the environmental vectors. The interpretation of the configuration is as follows: the vector 'distance' (vector no. 2) has a small angle with axis 1 and is thus correlated with axis 1. 'wave-exposure' (5) is correlated with axis 2, and 'depth' (3) is correlated with both axes. The variable 'time of sampling', or 'day no'. (11) is also correlated with both axes, but since the vector is much shorter the correlation is weak, whereas those with depth are strong. However, the factor 'time of sampling' appears to be highly correlated with the third compositional axis.

Since the main line of variation in the sample points runs roughly in the same direction as the vector 'depth' we can conclude that depth (and not distance) is the main environmental variable explaining compositional variation. Bottom type and wave-exposure can be said to be the vectors explaining most of the residual variation as they run perpendicular to the depth vector (cf. Fig. 5).

Fig. 8 shows some isolines for the main environmental variables based on the values for these variables in the various samples. The patterns for depth, bottom type and degree of wave exposure are clear. Samples from shallow depths are gathered in the lower left corner getting increasingly deep along the diagonal of the axes. Within each depth interval, samples are sorted according to wave exposure and bottom type. Thus, the most wave-exposed sites and the hardest' bottoms are found in the upper half of each depth interval. The pattern for belts is more complicated because it expresses a 2 -dimensional relation, exactly as described above in relation to the community configuration. One may even discern a third dimension here as exposure includes a distinct 'subgradation' within different bottom types causing the distinction of Fucus and Ceramium belts, clusters 4, 7, 23 versus 5, 19, 17 . 11, whereas Zostera marina belts substitute Fucus vesiculosus belts on soft-bottomed, sheltered localities of intermediate depth.

The differentiation along axis 3 of the DCCA analysis (not shown here) appears to be entirely determined by taxa which were found in 1974 samples but not in 1975 , and vice versa (see 'Discussion').

The taxa with positions near the end of environmental vectors are highly correlated with the corresponding variables. Obviously taxa with such high correlation are mostly rare taxa, which had little influence on the result of the classification, and these are not included in Table 1. Only at the negative end of the depth range, i.e. at the shallow sites, do we find a number of more important taxa, exactly those characterizing cluster group A (Table 1). Also along the vector 'bottom type' we observe some highly correlated more frequent taxa with Zostera marina and some other macrophytes as soft-bottom taxa, and Balanus improvisus and most of the red algae as hard-bottom taxa

Taxa with low correlation with any of the environmental variables are situated near the centroid of the diagram. There we expect and find the common taxa which hardly differentiate between community types (i.e. they occur in most of the samples) such as Mytilus 
Fig. 7. Species distribution along the first and second axis of the DCCA analysis. Species code numbers up to 40 are plant taxa, higher numbers are animals (code list of major species, see Table 1 and Fig. 3). Environmental vectors are indicated going from the centroid of the cluster Their length and direction indicates their importance for the observed distribution pattern and their angle to each other their mutual dependency, right angle meaning total independence. Encircled are no. of environmental vectors: 1 , profile no.; 2 , distance from shore; 3 , depth; 4 , bottom type; 5, wave exposure; 6 , silt; 7 , compass direction; 8 , bottom slope; 9 , belt code; 10 , cover degree; 11 , day no.; 12 , region

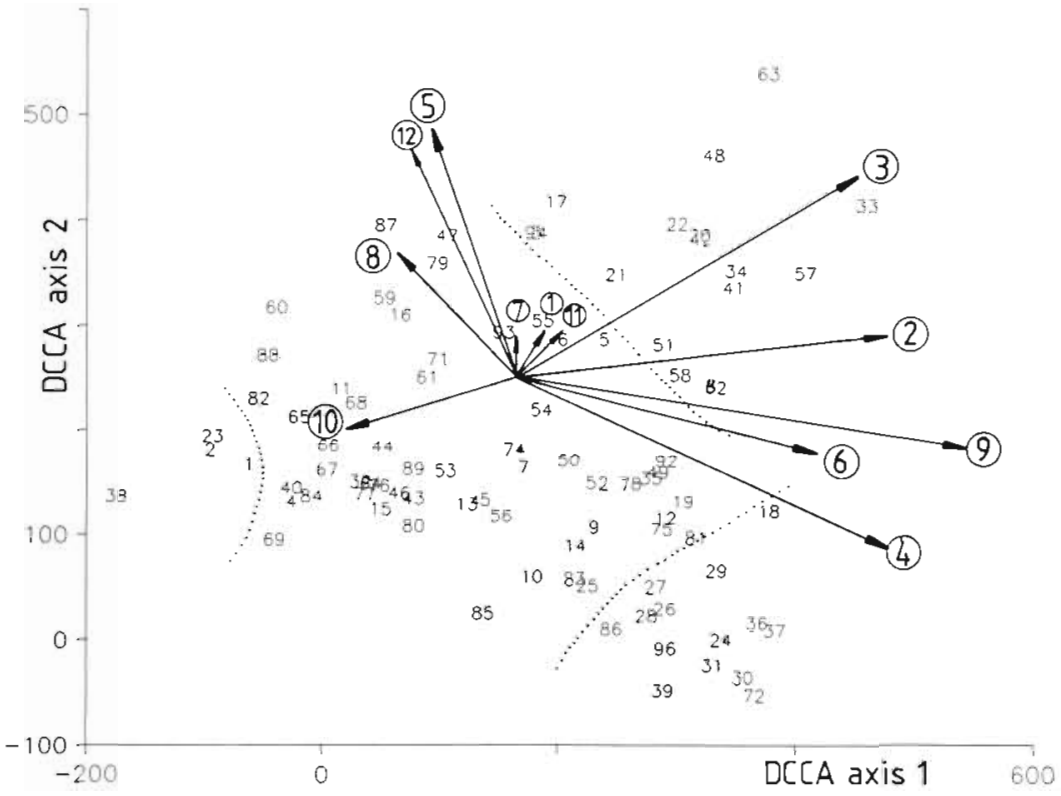

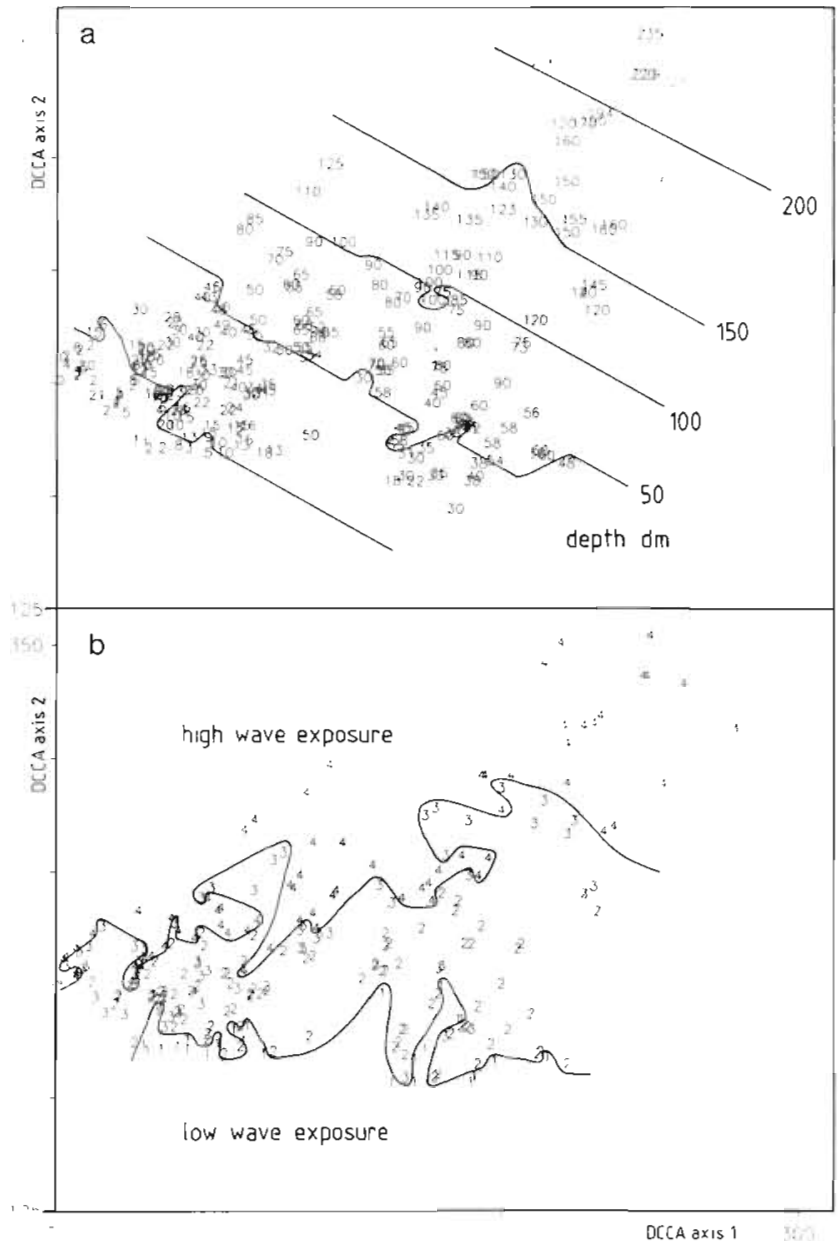

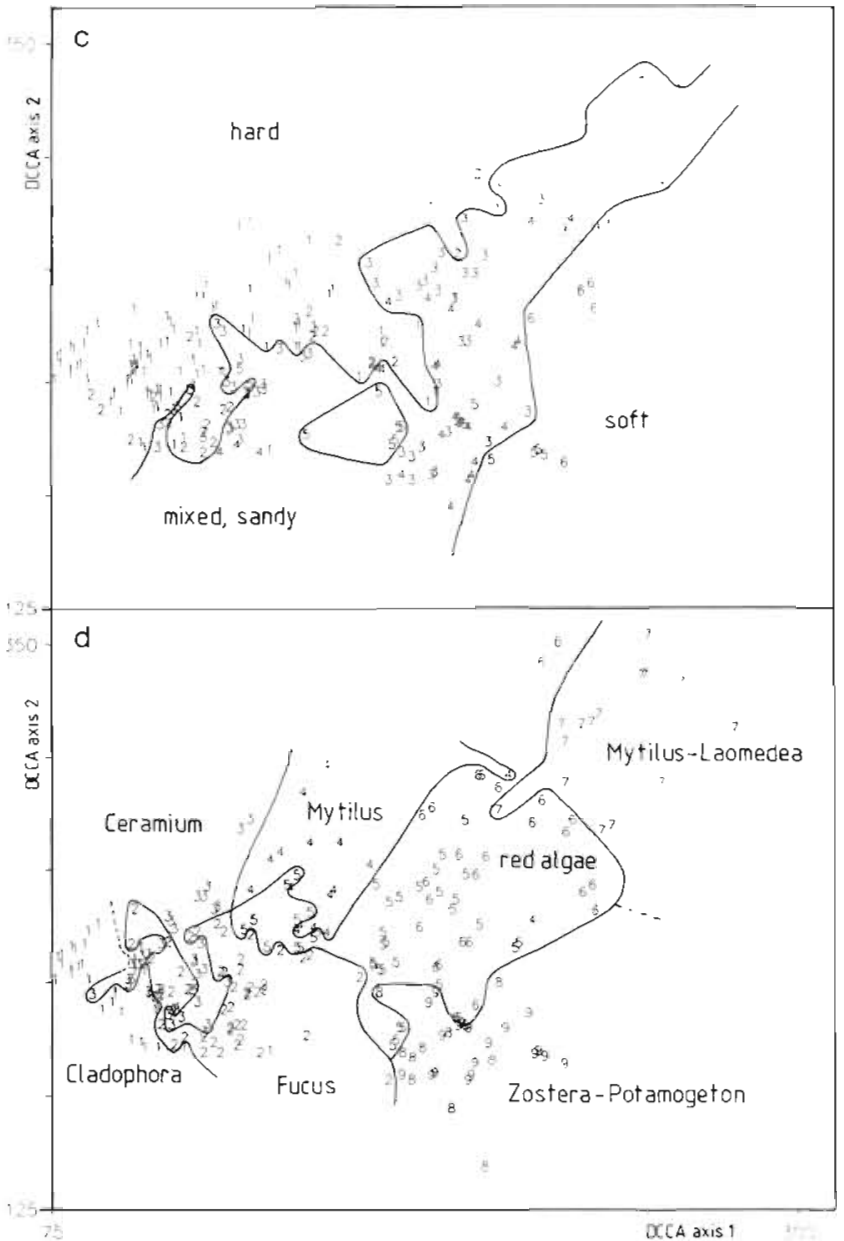

Fig. 8. Sample distribution along the first and second axis of the DCCA analysis. Equal (a) depth, (b) wave exposure, (c) bottom type and (d) belt code of each sample is indicated with isolines. Belt code given in Fig. 2 
edulis, Gammarus spp., Hydrobia spp. and Ceramium tenuicorne. Rare species sporadically occurring in 'extreme' situations (e.g. at the surface or deep down, high exposure) are found at the periphery of the figure.

The species distribution determined by species axes 1 and 2 in the DCCA-analysis separates both animal and plant species well and in a similar manner expected from their occurrence in different belts (Fig. 7). Thus we find species typical for the surface belts on the left of the figure, whereas species found almost only on deeper bottoms are plotted in the upper right part of the figure. The characteristic species of soft bottoms are almost exclusively found in the lower right part of the figure. The species found in most samples have no predictive value, and therefore are found in the vicinity of the centroid. The environmental vectors further emphasize these observations. For instance, the amphipod Calliopius rathkei (sp. no. 60) is found in the upper left part of the figure where the vectors indicate low depth (surface), high exposure to waves and hard bottoms with high bottom slope. This is precisely the environment where this amphipod is found in the Asko area. In a similar manner, the brown algae Scytosiphon lomentaria (sp. no. 38) occurs predominantly in spring just at the surface. It is found at the extreme left of the figure, whereas the isopod Mesidothea entomon (sp. no. 63) and the polychaete Harmothoe sarsii (sp. no. 48) are found on deep, silt rich bottoms on rare occasions. Also, the red algae Callithamnion roseum (sp. no. 33) is rarely found at deeper sites growing on stones and rocks or as epiphytes.

\section{DISCUSSION}

Our main question was: do patterns of variation in phytobenthic community composition occur and can these be related to environmental variation. The answer to this is clearly positive. Patterns of variation are found and, as in terrestrial plant ecology, both discontinuous and continuous variation occurs

Discontinuous variation is expressed in the cluster structure showing clear patterns of co-occurrence of certain taxa and relatively sharp contours between adjacent clusters. Such patterns may be determined by (1) sharp transitions between environmental zones and correlations of certain species to a particular zone, (2) positive interactions between species co-occurring under certain environmental conditions, and (3) negative interactions between (dominating) species occurring at different intervals along environmental gradients and showing competitive exclusion in zones of overlap.

Following the null-hypothesis approach as developed in island ecology (e.g. Connor \& Simberloff
1979, Strong 1980) Noy-Meir \& Van der Maarel (1987) distinguished 3 levels in the process of null-hypothesis testing in plant community ecology: (1) species combinations occur at sites independently and at random (2) observed co-occurrences are determined only by the overlap, or segregation in the species distribution over habitats, and the distributions are all independent of each other; (3) co-occurrences are determined by interactions between species, either competition or facilitation.

Clearly, null-hypothesis 1 can be rejected in our case, whereas we cannot yet decide on 2 and/or 3 . In other words, it is impossible to deduce any form of the results. On the other hand, it is possible to check the amount of discontinuity in the environment through observing the changes in environmental factors along the transects,

Apart from the local discontinuities brought about by topographic elevations and depressions the main gradient, water depth, is very steep indeed (Jansson 1973). Since gradients in environmental factors are much sharper under water than on land, this will result in a very sharp zonation in benthic communities also, e.g. light and wave force decrease rapidly and siltation increases with depth, leading to a change of hard bottoms to soft bottoms.

Hypothesis 2 may not always be true as some species follow each other very closely, for instance in the study area Elachista fucicola, when present, only grows on Fucus vesiculosus. There is also a general trend that samples taken in the Fucus belt contain more species, Fucus thus facilitating their occurrence. Fucus increases substrate heterogeneity and diversity by increasing shelter and offering substrate area for epiphytes and epizooes, and food for fish (Haage 1975).

The findings of various authors would indicate a dependence in species distribution in favor of hypothesis 3 (e.g. Möller et al. 1985. Seed 1985, Bell \& Westoby 1986, Pihl 1986, Johnson \& Scheibling 1987).

The zonation patterns observed in nature have proven to be fairly constant, resistant and resilient (cf. Lewis 1964, Stephenson \& Stephenson 1972, Hiscock \& Mitchel 1980, Dayton et al. 1984, Novaczek \& McLachlan 1986). The literature to date gives no conclusive explanation of what is determining the zonation patterns of intertidal and subtidal communities. Partly depending on the scale of observation it is concluded that the zonation pattern is set by environmental factors (cf. Lewis 1964. Stephenson \& Stephenson 1972, Dayton 1985, Lundälv 1985. Underwood 1985, Choat \& Andrew 1986) and/or by biotic interactions (cf. Dayton 1971, Paine 1977, 1984, Newell 1979, Underwood \& Denley 1984, Hiscock 1985).

The good correlations of observed patterns to environmental vectors in our material would indicate 
that zonation patterns observed in the Baltic Sea are to a large extent ruled by abiotic factors. Thus, ice abrasion and light limit the distribution of for instance Fucus vesiculosus (Kautsky et al. 1986) and the occurrence of hard substrate checks the distribution of Mytilus edulis (Kautsky 1982). On the other hand, the high abundance of $M$. edulis on hard bottoms in the Baltic is due to the absence of predators eating it.

Our study showed that depth (light) is the major environmental vector determining plant species distribution and animals associated to the plants. Also, bottom type and wave exposure are important. This is in accordance with Hiscock (1985) who concluded that light is thought to be the predominant factor determining which community occurs at different depths. Velimirov et al. (1977) used classification and ordination techniques in analyzing kelp bed communities. They found that depth, and at the most wave-exposed, offshore stations, bottom slope were important. Shepherd \& Womersley (1981), in analysing subtidal algae and seagrass communities, found that the distribution, together with that of the dominant and common species, is related to substrate, degree of water movement and depth. Ordination and factor analysis used in freshwater littoral communities indicated, that depths, bottom type and eutrophication status were primary correlative factors controlling distribution of submersed macrophytes (Collins et al. 1987)

Another question which received a clear answer is that regarding a different diagnostic significance for plants and animals. The sessile plants with few exceptions such as Ceramium tenuicorne occupy smaller ranges along the gradient than the animals. Still, sufficient animals show similar discontinuities to make them indispensable for an overall typology of benthic communities. The belts observed and named in the field were generally neatly grouped into different clusters by the various analyses, and environmental vectors followed expected gradients. Some species unique to the different clusters, as presented in Table 2, may not be so useful in field work, as they are hard to observe and/or difficult to identify by divers. The detection of conspicuous species, giving belts their name, is more practical and the belts still show correlations with the pattern generated by multivariate analyses.

The use of canonical correspondence analysis enabled us to check the possible significance of external variables. It appears to be worthwhile including nonenvironmental factors in the list of external variables and checking to what extent the compositional variation in the sample set is related to sampling characteristics and how such a relation can be interpreted. In our case the time of sampling, or rather whether the sample was taken in 1974 or 1975, appeared to be important enough to determine the third axis of variation in our DCCA ordination. In this case the interpretation was straightforward: certain species show abundance peaks in certain years - or the opposite trend - depending on severity of the winter and ice period, duration of weather-dependent low water periods and temperature during spring and early summer.

The main diagram of DCCA showed an interesting, more generally occurring phenomenon which has not received sufficient attention (cf. Van der Maarel 1969) in the interpretation of ordination diagrams, i.e. partial relationships between ordination axes and environmental factors. The main variation is found along a diagonal running roughly from taxon 38 to taxa 33 and 63 , i.e. parallel to the opposed vectors depth and cover (Fig. 7). The second line of variation, from taxon 87 to 72 , and linked with bottom type, is only significant in the middle range of vector complex 1 . In other words, the differentiating influence of bottom type is only effective for medium situations as regards depth (Fig. 6b). The diagonal beginning (shallow, irregularly dried out and ice-scraped) and end (deep, low light intensity) have extreme environmental situations, permitting but a few (a single) belts to occur, whereas the medium situation, having more moderate environmental factors due to intermediate depth, permits various belts to be present, from Ceramium-belts at the most wave-exposed sites through Fucus belts to Zostera-Potamogeton belts at the sheltered, sandy and soft localities.

Finally we discuss the resulting community and environmental structure in terms of the system of belts as usually distinguished in marine zonation patterns. Two questions are of interest: (1) To what extent is the occurrence of the belts reflected in the multivariate approach? (2) What information provided by the new approach was not already obvious from the belt structure?

It has appeared that the belts observed and named in the field were generally neatly grouped into different clusters placed along axes describing expected gradients. The environmental vectors were ranked according to importance and helped in the discussion of finding factors ruling an observed zonation pattern.

The importance of time of sampling which dominated axis 3 was a new interpretation. Another new finding was the high resemblance between the Fucus belt and the Zostera-Potamogeton belt, which have many of the same species but differ in habitat. As these species grow higher than other species in the area, they might offer more shelter and secondary hard substrate.

\section{CONCLUSIONS}

The results, being in accordance with what was previously known from this particular material, show that the analyses used in this paper are of help in interpret- 
ing complex data from the phytobenthic zone, giving ecologically relevant results. Such analysis would help marine ecologists to interpret unknown material, correctly revealing species assemblages (belts or zones), and highlight environmental factors which may cause the patterns observed.

With regard to our initial questions, numerical analysis of the material indicates that the zonation pattern observed in the Askö area of the Baltic Sea is primarily determined by abiotic factors such as depth (light), bottom type and wave exposure, listed in order of importance. Biotic interactions are of little importance. Initially, the occurrence of species in the Baltic Sea is determined by salinity excluding many marine and freshwater species from the area.

As gradients under water are very sharp, zonation patterns in benthic communities are clearly observed. Various phytobenthic communities are easily detected by the numeric methods used. Their distributions along the main axis of variation are clear, and environmental vectors help interpreting results. Thus a typical summer situation in the Askö area would be as follows (Fig. 2): An annual Cladophora belt is formed on shallow hard bottoms from the surface down to about $0.5 \mathrm{~m}$ depth. At intermediate depths (about 0.5 to $6 \mathrm{~m}$ ), on hard to boulder-stone bottoms a Fucus belt is found. This is replaced by a Ceramium belt at the most waveexposed, hard bottoms, and on sheltered sand to soft bottoms by a Zostera-Potamogeton belt. At deeper sites (about 5 to $15 \mathrm{~m}$ ), red algae dominate together with patches of dense stands of Mytilus edulis. $M$. edulis together with Laomedea spp. form the deepest communities on hard substrate (about 15 to $25 \mathrm{~m}$ depth).

\section{LITERATURE CITED}

Barton, D. R., Carter, J. C. H. (1982). Shallow-water epilithic invertebrate communities of eastern Georgia Bay, Ontario, in relation to exposure to wave action. Can. J. Zool. 60: 984-993

Bell, J. D., Westoby, M. (1986). Abundance of macrofauna in dense seagrass is due to habitat preference, not predation. Oecologia (Berl.) 68: 205-209

Boesch, D. F. (1973). Classification and community structure of macrobenthos in the Hampton Roads area, Virginia. Mar Biol. 21: 226-244

Branch, G. M. (1984). Competition between marine organisms: ecological and evolutionary implications. Oceanogr. mar. Biol. A. Rev 22: 421-593

Buhl-Jensen, L. (1986). The benthic amphipod fauna of the west-Norwegian continental shelf compared with the fauna of five adjacent fjords. Sarsia 71 193-208

Chardy, P., Glemarec, M., Laurec, A. (1976). Application of inertia methods to benthic marine ecology: practical implications of the basic options. Estuar cstl mar Sci 4: 179-205

Choat, J. H. Andrew, N. L. (1986). Interactions amongst species in a guild of subtidal benthic herbivores. Oecologia (Berl.) 68 (3): 387-394
Collins, C. D., Sheldon, R. B., Boylen, C. W. (1987). Littoral zone macrophyte community structure: distribution and association of species along physical gradients in Lake George, New York, U.S.A. Aquat. Bot. 29: 177-194

Connor, E. F., Simberloff, D. (1979). Assembly of species communities: chance or competition? Ecology 60; 1132-1140

Dayton, P. K. (1971). Competition, disturbance and community organization: the provision and subsequent utilization of space in a rocky intertidal community. Ecol. Monogr. 41: 351-389

Dayton, P. K. (1985). Ecology of kelp communities. A. Rev. Ecol. Syst. 16: 215-245

Dayton, P. K., Currie, V., Gerrodette, T., Keller, B. D., Rosenthal, R., Tresca, D. V. (1984). Patch dynamics and stability of some California kelp communities. Ecol. Monogr. 50 (3): 253-289

Digby, P. G. N., Kempton, R. A. (1987). Multivariate analysis of ecological communities. Chapman \& Hall, London, New York

Dybern, B. I., Ackefors, H., Elmgren, R. (1976). Recommendations on methods for marine biological studies in the Baltic Sea. Baltic Marine Biologist (BMB) 1: 1-98

Field, J. G., Clarke, K. R., Warwick, R. M. (1982). A practical stratcgy for analysing multispecies distribution patterns. Mar Ecol. Prog. Ser 8: 37-52

Field, J. G.. McFarlane, G. (1968). Numerical methods in marine ecology 1. A quantitative 'similarity' analysis of rocky shore samples in False Bay, South Africa. Zoologica african. 3 (2): 119-137

Field, J. G., Robb, F. T (1970). Numerical methods in marine ecology 2. Gradient analysis of rocky shore samples from False Bay. Zoologica african. 5 (2): 191-210

Gauch Jr, H. G. (1982). Multivariate analysis in community ecology. Cambridge University Press, Cambridge, London, New York

Giller, P. G. (1984). Community structure and the niche. Chapman and Hall, London, New York

Gray, J. S., Aschan, M., Carr, M. R., Clarke, K. R., Green, R. H., Pearson, T H., Rosenberg, R., Warwick, R. M. (1988). Analysis of community attributes of the benthic macrofauna of Fierefjord/Langesundfjord and in a mesocosm experiment. Mar. Ecol. Prog. Ser 46: 151-165

Haage, P. (1975). Quantitative investigations of the Baltic Fucus belt macrofauna. 2. Quantitative seasonal fluctuations. Contribution Askö Lab., Univ. Stock. 9: 1-88

Hällfors, G., Niemi, A., Ackefors, H., Lassig, J., Leppäkoski, E. (1981). Biological Oceanography. In: Voipio, A. (ed.) The Baltic Sea. Elsevier Sci. Publ. Comp. Amsterdam, Oxford, New York, p. 219-274

Hill, M. O. (1979a). DECORANA-A FORTRAN program for detrended correspondence analysis and reciprocal averaging. Cornell University, Ithaca, New York

Hill, M. O. (1979b). TWINSPAN-A FORTRAN program for arranging multivariate data in an ordered two-way table by classification of the individuals and attributes. Comell University, Ithaca, New York

Hill, M. O., Gauch Jr, H. G. (1980). Detrended correspondence analysis, an improved ordination technique. Vegetatio 42: 47-58

Hiscock. K. (1985). Aspects of the ecology of rocky sublittoral areas. In: Moore, P. G., Seed, R. (eds.) The ecology of rocky coasts. Hodder and Stougton, London, Sydney, Auckland, Toronto, p. 290-328

Hiscock, K. Mitchell, R. (1980). The description and classification of sublittoral epibenthic ecosystems. In: Price, J. H., Irvine, D. E. G., Farnham, W. F. (eds.) The shore environment Vol. 2. Ecosystems. Academic Press, London, New York, p. 323-370 
Hughes, R. N., Peer, D. L., Mann, K. H. (1972). Use of multivariate analysis to identify functional components of the benthos in St. Margaret's Bay, Nova Scotia. Limnol. Oceanogr. 17 (1): 111-121

Jansson, A. M. (1973). Depth distribution and bottom types in the primary research area of the Askö Laboratory. Askö Laboratory, mimeo. p. 1-17

Jansson, A. M., Kautsky, N. (1977). Quantitative survey of hard bottom communities in a Baltic archipelago. In: Keegan, B. F., Ceidigh, P. O., Boaden, P. J. S. (eds.) Biology of benthic organisms. Pergamon Press, New York, p. $359-366$

Jansson, B.-O. (1984). Baltic Sea ecosystem analysis: critical areas for future research. Limnologica, Berlin 15: 237-252

Jansson, B.-O., Wilmot, W., Wulff, F. (1984). Coupling the subsystems - the Baltic as a case study. In: Fasham, M. J. R. (ed.) Flows of energy and materials in marine ecosystems. Plenum Publishing Corporation, New York, p. 549-595

Jensén, S., Van der Maarel, E. (1980). Numerical approaches to lake classification with special reference to macrophyte communities. Vegetatio 42: 117-128

John, D. M., Lieberman, D., Lieberman, M., Swaine, M. D. (1980). Strategies of data collection and analysis of subtidal vegetation. In: Price, J. H., Irvine, D. E. G., Farnham, W. F. (eds.) The shore environment Vol. 1. Methods. Academic Press, London, New York, p. 265-284

Johnson, S. C., Scheibling, R. E. (1987). Structure and dynamics of epifaunal assemblages on intertidal macroalgae Ascophyllum nodosum, and Fucus vesiculosus in Nova Scotia, Canada. Mar. Ecol. Prog. Ser 37: 209-227

Kautsky, N. (1981). On the trophic role of the blue mussel (Mytilus edulis L.) in a Baltic coastal ecosystem and the fate of the organic matter produced by the mussels. Kieler Meeresforsch. Sonderh. 5: 454-461

Kautsky, N. (1982). Growth and size structure in a Baltic Mytilus edulis population. Mar. Biol. 68: 117-133

Kautsky, N., Kautsky, H., Kautsky, U., Waern, M. (1986). Decreased depth penetration of Fucus vesiculosus L. since the 1940's indicates eutrophication of the Baltic Sea. Mar. Ecol. Prog. Ser. 28: 1-8

Kullenberg, G. (1983). The Baltic Sea. In: Ketchum, B. H. (ed.) Estuaries and enclosed seas. Elsevier Sci. Publ. Comp., Amsterdam, Oxford, New York, p. 309-335

Legendre, L., Legendre, P. (1983). Numerical ecology. In: Jørgensen, S. E. (ed.) Developments in environmental modelling, 3. Elsevier Scientific Publ. Comp., Amsterdam, Oxford, New York

Lewis, J. R. (1964). Ecology of rocky shores. English Univ. Press, London

Lie, U. (1978). The quantitative distribution of benthic macrofauna in Fanafjorden, western Norway. Sarsia 63: 305-316

Lindström, S. C., Foreman, R. E. (1978). Seaweed associations of the Flat Top Islands, British Columbia: a comparison of community methods. Syesis 11: 171-185

Lundälv, T. (1985). Detection of long-term trends in rocky sublittoral communities: representativeness of fixed sites. In: Moore, P. A., Seed, R. (eds.) The ecology of rocky coasts. Hodder and Stoughton, London, Sydney, Aukland, Toronto, p. 329-345

Lüning, K. (1985). Meeresbotanik. Georg Thieme Verlag, Stuttgart, New York

Magaard, L., Reinheimer, G. (1974). Meereskunde der Ostsee. Springer Verlag, Berlin, Heidelberg, New York

Malmgren, B., Oviatt, C., Gerber, R., Jeffries, H. P. (1978). Correspondence analysis: applications to biological oceanographic data. Estuar. cstl mar. Sci 6: 429-437
McLachlan, A. C., Cockcroft, A. C., Malan, D. E. (1984) Benthic faunal response to a high energy gradient. Mar. Ecol. Prog. Ser. 16: 51-63

Möller, P., Pihl, L., Rosenberg, R. (1985). Benthic faunal energy flow and biological interactions in some shallow marine soft bottom habitats. Mar. Ecol. Prog. Ser. 27: 109-121

Murray, S. N., Littler, M. M. (1981). Biogeographical analysis of intertidal macrophyte floras of southern California. J. Biogeogr. 8: 339-351

Neushul, M. (1967). Studies of subtidal marine vegetation in western Washington. Ecology 48 (1): 83-94

Newell, R. C. (1979). Biology of intertidal animals, 3rd edn. Marine Ecological Surveys Ltd, Faversham, Kent

Novaczek, I., McLachlan, J. (1986). Recolonization by algae of the sublittoral habitat of Halifax County, Nova Scotia, following the deminse of sea urchins. Botanic mar. 29 (1): $69-73$

Noy-Meir, I., Van der Maarel, E. (1987). Relations between community theory and community analysis in vegetation science: some historical perspectives. Vegetatio 69 : 5-15

Oviatt, C. A., Perez, K. I., Nixon, S. W. (1977). Multivariate analysis of experimental marine ecosystems. Helgoländer wiss. Meeresunters. 30: 30-46

Paine, R. T. (1977). Controlled manipulations in the marine intertidal zone, and their contributions to ecological theory. In: Goulden, C. E. (ed.) The changing scenes in natural sciences, 1776-1976. Natn. Acad. Sci. USA, Spec. Publ. no 12, p. 245-270

Paine, R. T (1984). Ecological determinism in the competition for space. Ecology 65 (5): 1339-1348

Pihl, L. (1986). Exposure, vegetation and sediment as primary factors for mobile epibenthic faunal community structure and production in shallow marine soft bottom areas. Neth. J. Sea Res. 20 (1): 75-83

Poore, G. C. B., Mobley, M. C. (1980). Canonical correlation analysis of marine macrobenthos survey data. J. exp. mar. Biol. Ecol. 45: 37-50

Russel, G. (1980). Applications of simple numerical methods to the analysis of intertidal vegetation. In: Price, J. H., Irvine, D. G. E., Farnham, W.F. (eds.) The shore environment Vol. 1. Methods. Academic Press, London, New York, p. $171-192$

Schiel, D. R., Foster, M. S. (1986). The structure of subtidal algal stands in temperate waters. Oceanogr. mar biol. A. Rev. 24: 265-307

Seed, R. (1985). Ecological pattern in the epifaunal communities of coastal macroalgae. In: Moore, P. A., Seed, R. (eds.) The ecology of rocky coasts. Hodder and Stoughton, London, Sydney, Aukland, Toronto, p. 22-35

Shepherd, S. A., Womersley, H. B. S. (1981). The algal and seagrass ecology of Waterloo Bay, South Australia. Aquat. Bot. 11: 305-371

Siedler, G., Hatje, G. (1974). Temperatur, Salzgehalt und Dichte. In: Magaard, L., Rheinheimer, G. (eds.) Meereskunde der Ostsee. Springer Verlag, Berlin, Heidelberg, New York, p. 43-60

Stephenson, T. A., Stephenson, A. (1972). Life between tidemarks on rocky shores. W. H. Freeman and Co., San Francisco

Strong, D. R. (1980). Null hypotheses in ecology. Synthese 43 : 271-285

Ter Braak, C. J. F. (1985). CANOCO-FORTRAN program for canonical correspondence analysis and detrended correspondence analysis. IWIS-TNO, Wageningen

Ter Braak, C. J. F. (1986). Canonical correspondence analysis: a new eigenvector technique for multivariate direct gradient analysis. Ecology 67 (5): 1167-1179 
Ter Braak, C. J. F. (1987). The analysis of vegetation-environment relationships by canonical correspondence analysis Vegetatio 69: 69-77

Thom, R. M. (1980). A gradient in benthic intertidal algal assemblages along the southern California coast. J. Phycol 16: $102-108$

Tittley, I., Shaw, K. M. (1980). Numerical and field methods in the study of the marine flora of chalk cliffs. In: Price, J. H. Irvine, D. E. G., Farnham, W. F. (eds.) The shore environment Vol. 1 Methods. Academic Press, London, New York, p. 213-240

Underwood, A. J. (1985). Physical factors and biological interactions: the necessity and nature of ecological experiments. In: Moore, P. A., Seed, R. (eds.) The ecology of rocky coasts. Hodder and Stoughton, London Sydney, Aukland, Toronto, p. 372-390

Underwood, A. J., Denley, E. J. (1984). Paradigms, explanations and generalizations in models for the structure of intertidal communities on rocky shores. In: Strong, D. R., Jr, Simberloff, D., Abele, L. G., Thistle, A. B. (eds.) Ecological communities: conceptual issues and the evidence. Princetown University Press, New Jersey, p. $151-180$

This article was submitted to the editor
Van der Maarel, E. (1969). On the use of ordination methods in phytosociology. Vegetatio 19: 21-46

Van der Maarel, E. (1979a). Transformation of cover-abundance values in phytosociology and its effect on community similarity. Vegetatio 39: 97-114

Van der Maarel, E. (1979b). Multivariate methods in phytosociology, with reference to the Netherlands. In: Werger, M. J. A. (ed.) The study of vegetation. Dr W. Junk Publishers, The Hague, p. 163-225

Van der Maarel, E., Espejel, I., Moreno-Casasola, P. (1987). Two-step vegetation analysis based on very large data sets. Vegetatio 68: 139-143

Van der Maarel, E., Janssen, J. G. M., Louppen, J. M. W (1978). TABORD, a program for structuring phytosociolog ical tables. Vegetatio 38 (3): 143-156

Velimirov, B., Field, J. G., Griffith, C. L., Zoutendyk, P. (1977). The ecology of kelp bed communities in the Benguela up. welling system. Helgoländer wiss. Meeresunters. 30 495-518

Weinstein, M. P., Brooks, H. A. (1983). Comparative ecology of nekton residing in a tidal creek and adjacent seagrass meadow: community composition and structure. Mar Ecol. Prog. Ser 12. 15-27

Manuscript first received: February 27, 1989 Revised version accepted: October 5, 1989 